\title{
ELABORAÇÃO, CARACTERIZAÇÃO FÍSICO-QUÍMICA E SENSORIAL DE BOLO FORMULADO COM FARINHA DAS VAGENS DE ALGAROBA
}

\author{
M. B. MUNIZ ${ }^{1}$, F. L. H. da SILVA², J. P. GOMES ${ }^{1}$, C. G. da SILVA², M. F. ALVES ${ }^{2}$, \\ V.de S. QUEIROZ ${ }^{2}$, F. C. dos S. LIMA ${ }^{3}$ \\ ${ }^{1}$ Universidade Federal de Campina Grande, Departamento de Engenharia Agrícola \\ ${ }^{2}$ Universidade Federal da Paraíba, Departamento de Engenharia Química \\ ${ }^{3}$ Instituto Federal de Educação Tecnológica. Departamento de Química
}

E-mail para contato: $\underline{\text { mbmmuniz@yahoo.com }}$

\begin{abstract}
RESUMO - O combate ao desperdício pode começar de maneira bem simples, como através do aproveitamento das partes tradicionalmente não usadas dos alimentos, visando diminuir o desperdício nutricional, com a utilização de partes vegetativas, assim, a vagem de algaroba (Prosopolis julifora), pode ser mais uma alternativa usada para o uso desse bom emprego. Nesse sentido, o objetivo desse trabalho foi estudar uma aplicação da farinha proveniente dos resíduos das vagens de algaroba, para a formulação do bolo. $\mathrm{Na}$ análise sensorial do bolo, constatou-se que, em nível de $5 \%$ de probabilidade, não existe diferença significativa ao aplicar-se o Teste de Tukey nos tratamentos.
\end{abstract}

\section{INTRODUÇÃO}

A algarobeira (Prosopis juliflora) é uma planta que concentra seu valor nutritivo nas vagens, que quando maduras possuem aproximadamente $84,0 \%$ de matéria seca. Vários são os estudos empregando a vagem de algaroba na alimentação animal (STEIN et al., 2009).

Em destaque o elevado conteúdo de proteínas, minerais, fibras e lipídios, cálcio, recomenda o consumo em casos de desnutrição, baixo peso e descalcificação e considerando a vagem da algaroba como um alimento completo, destacando também a composição rica em hidratos de carbono como a sacarose, maltose e amidos (elevado teor de açúcar, cerca de 30\%, o que lhes confere paladar agradável). Possuem em torno de $12 \%$ de proteína bruta. A goma é considerada seu constituinte mais nobre e corresponde a cerca de $30 \%$ da semente e $3 \%$ do peso da vagem. Teoricamente, chegase a uma produção de $300 \mathrm{~kg}$ de goma por hectare. Os açúcares solúveis do pericarpo de $P$. juliflora, do Equador se compõem de $75 \%$ de sucrose, $12 \%$ de frutose, $5 \%$ de glicose, $5 \%$ inositol e $1 \%$ de rafinose. A associação da farinha de algaroba com a farinha de arroz ou mesmo gritz de milho, quando são submetidas ao processo de extrusão, concede um bom produto, oferecendo uma boa qualidade ao alimento e a sua qualidade nutricional, Figueiredo et al. (2010). 
Desta forma, o presente trabalho teve como objetivo produzir um bolo de farinha dos resíduos das vagens de algaroba realizando a caracterização físico-química e testes sensoriais.

\section{MATERIAL E MÉTODOS}

Este trabalho foi conduzido no Laboratório de Engenharia Bioquímica (LEB) da Unidade Acadêmica de Engenharia Química UAEQ/CCT/UFCG e no Laboratório de Nutrição e Alimentação Animal (LNAA) do Departamento de Zootecnia - UFPB Campus de Areia, PB.

\subsection{Farinha de algaroba/produção de bolo}

Após ter sido peneirado, as frações sólidas das farinhas de 60 mesh $(0,25 \mathrm{~mm})$ e 80 mesh $(0,18 \mathrm{~mm}$ ) foram direcionadas para a produção dos dois bolos de acordo com a granulometria obtida. A farinha de algaroba foi pesada na proporção de 1/3 com relação à farinha de trigo, ou seja, 1 xícara de farinha de algaroba para duas xícaras de farinha de trigo. Cada ingrediente era pesado de acordo com os testes inicias para a fabricação do bolo. Depois foi realizada a mistura em batedeira doméstica até alcançar a homogeneidade com os outros ingredientes, açúcar, sal, ovos e manteiga para a formação do bolo (Tabela 1).

Tabela 1. Balanço de massa para o bolo com $35 \%$ da farinha de algaroba

\begin{tabular}{ccccccc}
$\begin{array}{l}\text { Farinha } \\
\text { de trigo }\end{array}$ & Leite & Açúcar & $\begin{array}{c}\text { Farinha de } \\
\text { algaroba }\end{array}$ & Manteiga & Ovos & Sal \\
\hline & & & $\%$ & & & \\
\hline 65 & 40 & 5 & 35 & 4 & 15 & 1,8 \\
\hline
\end{tabular}

A Figura 1 apresenta o fluxograma experimental do processo e caracterização físicoquímicas e sensorial dos resíduos da farinha da algaroba para a obtenção do bolo de algaroba em duas granulometrias (mesh 60 e 80).

\subsection{Descrição do processo da produção do bolo de algaroba}

\subsubsection{Fração sólida (farinha)}

Após ter sido secada, fracionada e peneirada, as frações sólidas das farinhas de 60 mesh $(0,25 \mathrm{~mm})$ e 80 mesh $(0,18 \mathrm{~mm})$ foram direcionadas para a formulação dos dois bolos de acordo com a granulometria obtida.

\subsubsection{Pesagem e mistura}

Em cada formulação do bolo, cada granulometria da farinha de algaroba (60 ou 80 mesh) foi realizada a pesagem proporcional a cada experimento. Em seguida foi 
realizada a mistura em batedeira caseira até alcançar a homogeneidade com os outros ingredientes, açúcar, sal, ovos e manteiga para a formação do bolo.

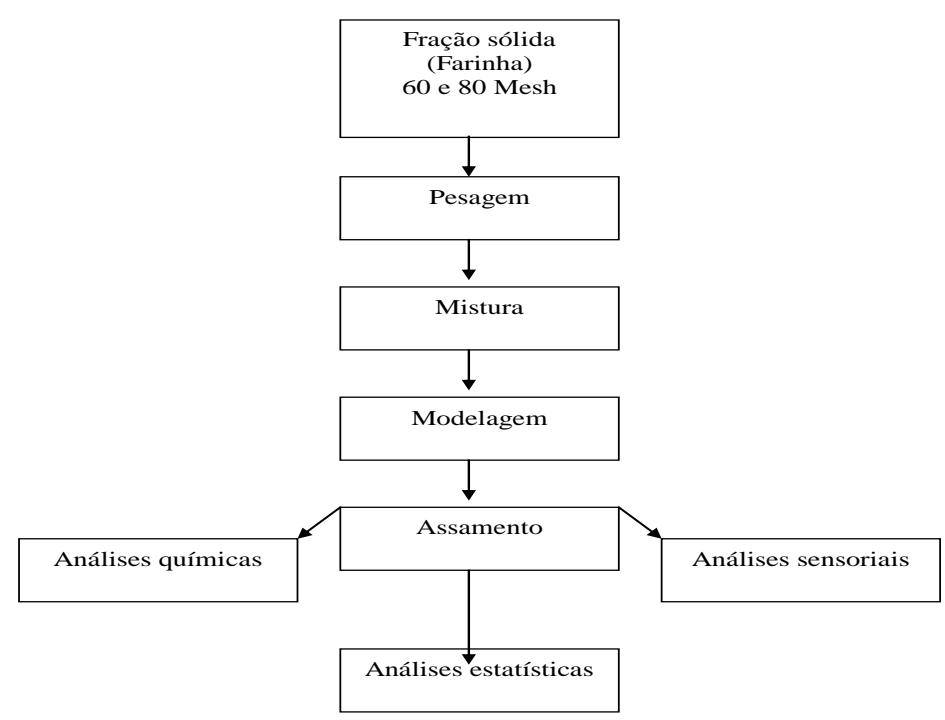

Figura 1. Fluxograma experimental para obtenção do bolo de resíduo de algaroba

\subsubsection{Modelagem e assamento}

A forma de alumínio usada para modelagem do bolo foi previamente untada com manteiga e pulverizado com a farinha de trigo e depois recebeu a mistura da massa e foi conduzida para assar num forno caseiro a uma temperatura de $240{ }^{\circ} \mathrm{C}$ por $20 \mathrm{~min}$. Depois de esfriado, o bolo foi desmoldado e assim, foi submetido às devidas análises.

\subsubsection{Análise sensorial}

A análise sensorial foi realizada na cidade do Recife, PE, na Sede da Entidade AMAS (Associação Menonita de Assistência Social), onde na oportunidade 40 provadores não treinados receberam orientações do procedimento das análises do bolo de algaroba e em seguida foram procedidas as avaliações quanto ao sabor, odor, textura e aroma. Foi repassada para cada provador uma ficha, onde eles avaliavam a aparência, odor, textura e sabor da amostra mesh $60(0,18 \mathrm{~mm})$, depois dava-se um tempo de cinco minutos em média para que houvesse um intervalo entre uma amostra e a outra, em seguida servia para os provadores uma bolacha de água e sal, para que houvesse a mascaração do sabor da amostra servida, e em seguida servia a amostra de 80 mesh $(0,14 \mathrm{~mm})$, repetindo o procedimento. No final da degustação foi solicitado para os provadores que caso houvesse algum comentário fosse acrescentado na parte final da ficha, conforme metodologia do Instituto Adolf Lutz (Brasil, 2005).

\subsubsection{Análise estatística}

Os dados experimentais obtidos na análise sensorial foram analisados estatisticamente com o uso do programa computacional Assistat, versão 7.5 beta (SILVA \& AZEVEDO, 2009). Foi utilizado o delineamento inteiramente casualizado 
com 2 tratamentos e 40 repetições. A comparação entre as médias dos dados foi feita através do teste de Tukey a 5\% de probabilidade.

\section{RESULTADOS E DISCUSSÃO}

\subsection{Bolo de algaroba}

A caracterização físico-química da farinha das vagens de algaroba (Tabela 2) se faz relevante, nesse estudo, uma vez que através dela tem-se um embasamento melhor para constituir quais são os componentes existentes na composição química de um produto que está sendo oferecido para a população.

Tabela 2. Composição físico-química das farinhas de $60(0,25 \mathrm{~mm})$ e $80 \mathrm{mesh}(0,18$ $\mathrm{mm}$ ) das vagens de algaroba.

\begin{tabular}{lcc}
\hline Componente & Farinha & Farinha \\
& 60 mesh & $\mathbf{8 0}$ mesh \\
\hline Umidade (\%) & $6,30 \pm 0,19$ & $6,18 \pm 0,25$ \\
Proteínas (\%) & $7,84 \pm 0,02$ & $7,63 \pm 0,01$ \\
Lipídeos (\%) & $3,11 \pm 0,0$ & $2,79 \pm 0,0$ \\
Acidez total (\%) & $6,70 \pm 0,47$ & $6,27 \pm 0,45$ \\
Minerais (\%) & $2,38 \pm 0,11$ & $2,25 \pm 0,04$ \\
FDN (\%) & 51,37 & 35,63 \\
FDA (\%) & 51,18 & 15,34 \\
Açúcares redutores totais & $46,45 \pm 0,68$ & $53,25 \pm 0,00$ \\
pH & $4,74 \pm 0,01$ & $4,71 \pm 0,00$ \\
Matéria Orgânica (\%) & 96,95 & 96,60 \\
Matéria Seca (\%) & 93,70 & 93,82 \\
Gordura bruta(\%) & 5,59 & 5,93 \\
\end{tabular}

Comparando os parâmetros analisados da caracterização físico-química da farinha com as duas granulometrias estudadas (Tabela 2), observa-se que, praticamente, em todos os parâmetros há uma semelhança de resultados.

De acordo com o trabalho de Oliveira (2009), o bolo elaborado com $10 \%$ de farinha de yacon apresentou o percentual de proteína de 7,09 \%, ou seja, bem próximo da farinha de algaroba, como também de um bolo padrão, que é proporcionado em torno de $7,78 \%$.

Para Guimarães et al. (2010), estudando a farinha da entrecasca da melancia a 7 e $30 \%$ para a produção de bolo, verificaram-se que a quantidade de proteína foi de 5,99 e $6,65 \%$ respectivamente. Comparando a farinha da entrecasca da melancia com a farinha de algaroba, o percentual de proteína é $26 \%$ menor. 
Para Fasolin et al. (2007), que trabalharam com a farinha de banana verde para produção de biscoito, observou que a umidade na composição da farinha era de $7,55 \%$, valor esse, próximo ao encontrado na farinha de algaroba, enquanto o valor de proteína foi de $4,54 \%$, ou seja, quase a metade da proteína encontrado na farinha de algaroba.

Estudo realizado por Bernadino (2011), com a farinha do bagaço da cana-deaçúcar em bolo, observou que o teor de proteína bruta foi de 1,67\%, FDN 81,94\%, FDA $50,63 \%$, e umidade de $1,37 \%$, se comparar esses valores com a farinha de algaroba, verifica-se que o teor de proteína e de umidade foram bem inferiores, quanto ao FDN o valor da farinha do bagaço da cana foi superior, e o FDA praticamente igual ao de 60 mesh da farinha de algaroba.

Do ponto de vista das características da composição físico-químico do resíduo da vagem de algaroba, pode-se afirmar que os componentes observados estão de acordo com as literaturas citadas, podendo os mesmos ser usados no constituinte da produção do bolo de algaroba oferecendo assim, uma melhor qualidade nutricional.

\subsection{Análise sensorial do bolo de algaroba}

Os perfis sensoriais para os atributos de aparência, aroma, textura e sabor percebidos pelos provadores não treinados para o bolo de algaroba de 60 e 80 mesh da farinha do resíduo de algaroba, atribuídos pelos 40 provadores não treinados estão apresentados nas Figuras 3 e 4. Estes resultados são referentes a análise sensorial para os dois tipos de bolo de algaroba correspondentes a escala hedônica, com nove atribuições, do desgostei a gostei muitíssimo referentes a aparência, aroma, textura e sabor.
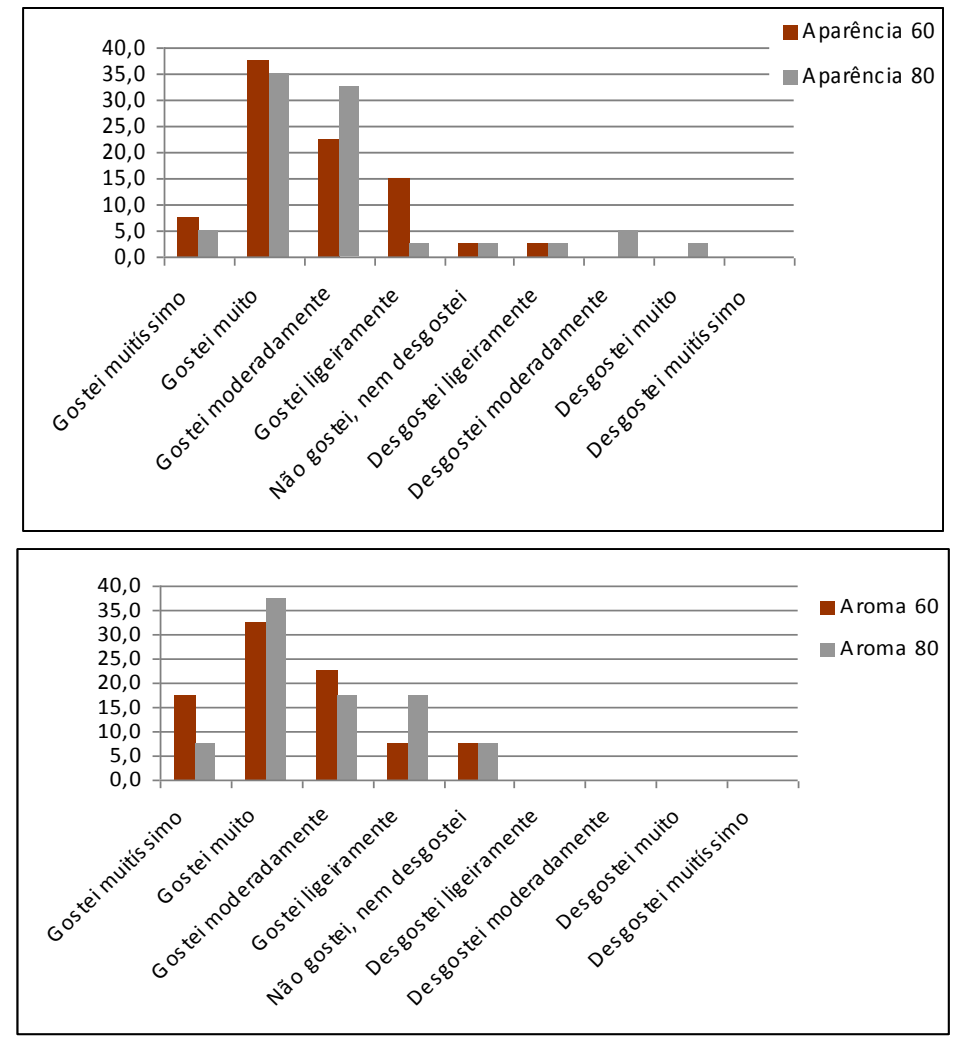
Figura 3. Perfil dos valores para aparência e aroma atribuídos ao bolo de algaroba para 60 e 80 mesh
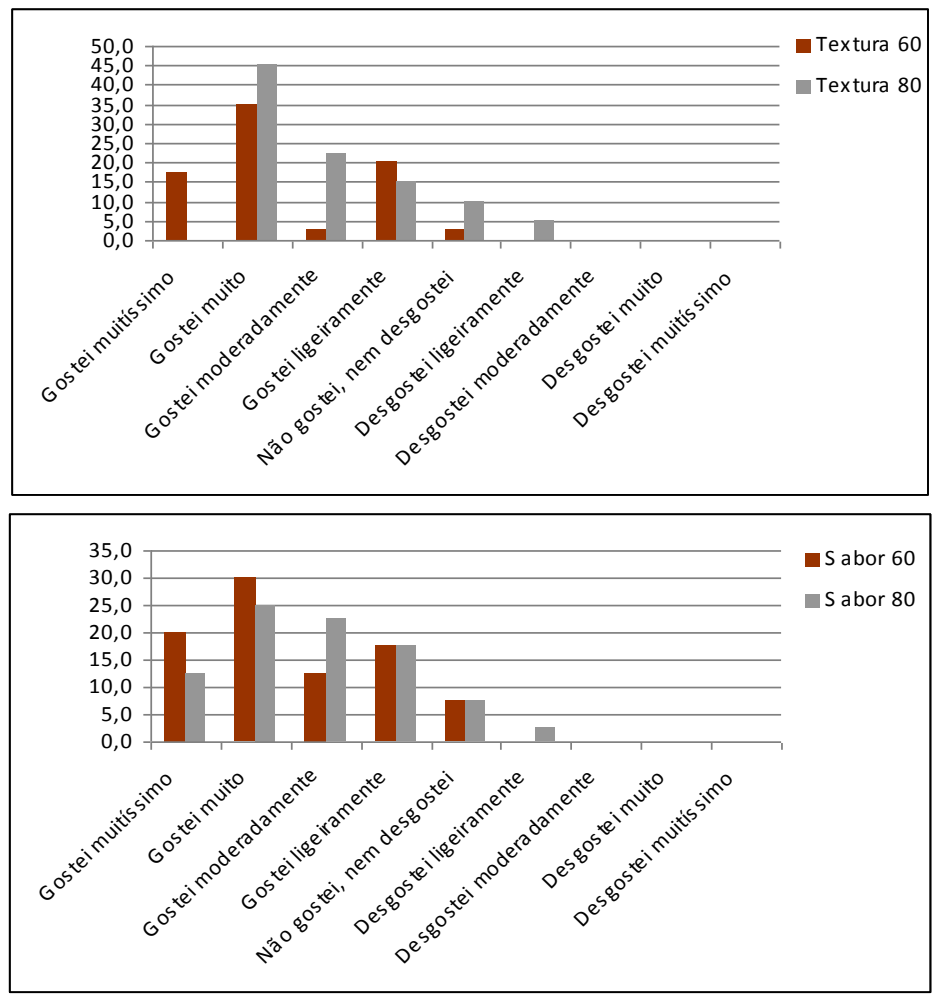

Figura 4. Perfil dos valores para textura e sabor atribuídos ao bolo de algaroba para 60 e 80 mesh.

Observa-se na Figura 3 que 37,5\% dos provadores gostaram muito da aparência do bolo de 60 mesh, enquanto 35\% gostaram do bolo de 80 mesh. Isso pode significar que o bolo que obteve o maior valor apresentou um ligeiro aspecto na exterioridade.

Para o perfil do aroma, foi verificado que $37,5 \%$ dos entrevistados gostaram muito do aroma do bolo de 80 mesh, enquanto 32,5\% gostaram muito do bolo de 60 mesh. Pode-se dizer que devido o bolo de 80 apresentar uma boa concentração de gomas do amido da algaroba, o aroma do bolo ficou mais ativo, fazendo que os provadores se identificassem mais com o aroma.

Nos valores atribuídos para a textura, observa-se que $45 \%$ dos provadores gostaram muito do bolo de 80 mesh, e 35\% gostaram mais do bolo de 60 mesh, isso pode significar que o bolo de 80 apresentou uma textura mais fina do que o de 60 mesh.

Observando a análise realizada para sabor, foi verificado que houve uma melhor aceitação para o bolo de 60 mesh, com valor de 30\% (gostei muito), enquanto que o bolo de 80 mesh teve a aceitação de $25 \%$ (gostei muito), é bom salientar que $20 \%$ dos provadores atribuíram o atributo (gostei muitíssimo) ao bolo de 60 mesh.

$\mathrm{Na}$ análise estatística para comparação da aparência para as granulometrias de 60 e 80 mesh, do resíduo das farinhas de algaroba, verificou-se que não houve diferença significativa entre os dois tratamentos. Para o aroma também, observou-se que não houve diferença significativa ao nível de $5 \%$ de probabilidade, mesmo que os 
provadores tenham aceitado mais o aroma do bolo de 80 mesh. Verifica-se também que não houve diferença significativa para o perfil de textura e nem para o sabor, apesar dos entrevistados terem gostado mais do sabor do bolo de 60 mesh.

As análises sensoriais mostraram que os bolos com as granulometrias diferentes não diferiram estatisticamente, porém houve uma melhor aceitação no sabor e aparência para o bolo de 60 mesh, pois o bolo de 80 mesh deixava um pouco de adstringência, devido ao teor de taninos contido na farinha da algaroba, porém os atributos textura e aroma, os provadores aceitassem mais o bolo de 80 mesh.

Independentemente dessas peculiaridades, tanto o bolo de 60 quanto o de 80 mesh foram bem aceitos pelos provadores que participaram da análise sensorial, mostrando assim, que esse produto pode ser disponibilizado no mercado.

\section{CONCLUSÃo}

A análise sensorial do bolo de 60 e 80 mesh, do resíduo das vagens de algaroba, para as avaliações de aparência, textura, aroma e sabor, não diferenciaram estatisticamente ao nível de 5\% de probabilidade do Teste de Tukey. A farinha de algaroba apresentou potencial para participar como ingrediente em formulação de bolos, pois os bolos produzidos com farinha de algaroba apresentaram características sensoriais agradáveis para os consumidores.

\section{REFERÊNCIAS BIBLIOGRÁFICAS}

BERNADINO, M. A., Caracterização e aplicação da farinha do bagaço da cana-deaçúcar em bolo. 2011, 83f. Dissertação (Mestrado em Engenharia de Alimentos) Universidade de São Paulo, 2011.

BRASIL. Ministério da Saúde. Agência Nacional de Vigilância Sanitária, Métodos Físico-químicos para análises de alimentos. Brasília: Ministério da Saúde, 2005. 1018p. (Série A. Normas Técnicas). IV edição.

FASOlin, L. H., AlMEIDA, G. C., CASTANHO, P. S., OliveIRA, E. R. N. Biscoitos produzidos com farinha de banana: avaliações química, física e sensorial. Ciênc. Tecnol. Aliment., Campinas, 27(3): 524-529, jul.-set. 2007.

FIGUEIREDO, A.A.; ASCHERI, J.L.R.; CARVALHO, C.W. Produção de expandidos à base de farinha mista de algaroba e arroz e de algaroba e milho. In: Congresso Brasileiro de Ciência e Tecnologia de Alimentos - Estratégia para o Desenvolvimento, 2004, Recife. Anais...Recife: SBCTA, 2010. CD-Rom.

GUIMARÃES, R. R., FREITAS, M. C. J.,SILVA, V. L. M. Bolos simples elaborados com farinha da entrecasca de melancia (Citrullus vulgaris, sobral): avaliação química, fisica e sensorial. Ciênc. Tecnol. Aliment. Campinas, 30(2): 354-363, abr.-jun. 2010. OLIVEIRA, R. C. S., VIEIRA, V. B., GRESSLER. C.., VIEGA, S., Elaboração de bolo com farinha de yacon. Ciência Rural, Santa Maria, v39, n.6, p. 1869-1872, set, 2009.

SANTOS S.C; ALMEIDA S.S.; TOLEDO A.L.; SANTANA J.C.C.; SOUZA R.R. Elaboração e análise sensorial do fermentado de acerola (Malpighia Punicifolia L.). Brazilian Journal of Food Technology, $5^{\circ}$ SIPAL, março, 2005. 
SILVA, F. de A. S. e. \& Azevedo, C. A. V. de. Principal Components Analysis in the Software Assistat-Statistical Attendance. In: WORLD CONGRESS ON COMPUTERS IN AGRICULTURE, 7, Reno-NV-USA: American Society of Agricultural and Biological Engineers, 2009.

STEIN, R. B. S. et al. Uso do farelo de vagem de algaroba (Prosopis juliflora (Swartz) D.C.) em dietas para eqüinos. Rev. Brasileira de Zootecnia, v. 34, n. 04, p. 1240-1247, 2009. 